\title{
The $\mathrm{JCl}$ gets a facelift
}

\section{A redesigned JCI makes its first appearance: a newly designed logo, a revised layout, more color, and creative use of fonts combine to make the journal an even better read.}

This issue of the JCI sports a fresh look. Alert readers will have noticed that we altered the cover design with the first issue of 2004, which incorporates a new logo for the journal. The present issue introduces the full redesign, and there are changes to come in the presentation of the JCI on the Web and in other venues.

The time was right for a different visual aesthetic - the redesign doesn't simply represent change for change's sake. During the past few years, the JCI has added sections devoted to subjects well beyond the sphere of research articles and Perspective Series. This effort includes more content of interest to the casual reader, as well as the Science in Medicine and Science and Society sections, in-depth treatments of the impact of science on areas directly relevant to our lives (1). With the old style, it was becoming harder to go in new directions visually, and the redesign gives the JCI a new map to follow.

Throughout the journal, the redesign places more emphasis on titles and figures, and it highlights sections by bolding or justifying text to help draw the eye to specific content. Different fonts are used to demarcate figure legends or references in order to ease readability. The space of the page is used to the fullest extent, without appearing crammed or cluttered. Letter spacing, fonts, the use of color, and the environment surrounding the text (white spaces, boxes, and lines) needed to be rethought, and we have done just that. The JCI has tended toward a "classic" look, which is understandable given its longevity as a publication. The redesign dispenses with those elements that are outdated and retains those that make sense, resulting in pages that are, we hope, more interesting. The new appearance also gives us a chance to improve organization and navigation through information through better treatment of text and figures and an intelligent combination of the two.

There were many considerations that went into the redesign, but two among them merit more than superficial comment. Increasingly, our readers are not making treks to a library or waiting by their mailboxes for their issues of the JCI. They are notified about new issues when they receive tables of content by e-mail. They learn about articles of interest through topical or subject e-mail alerts. They find JCI articles through PubMed searches or via citations in articles from other journals. As monthly online readership exceeds 55,000 unique users, which is well ahead of the 5,000 or so subscribers to
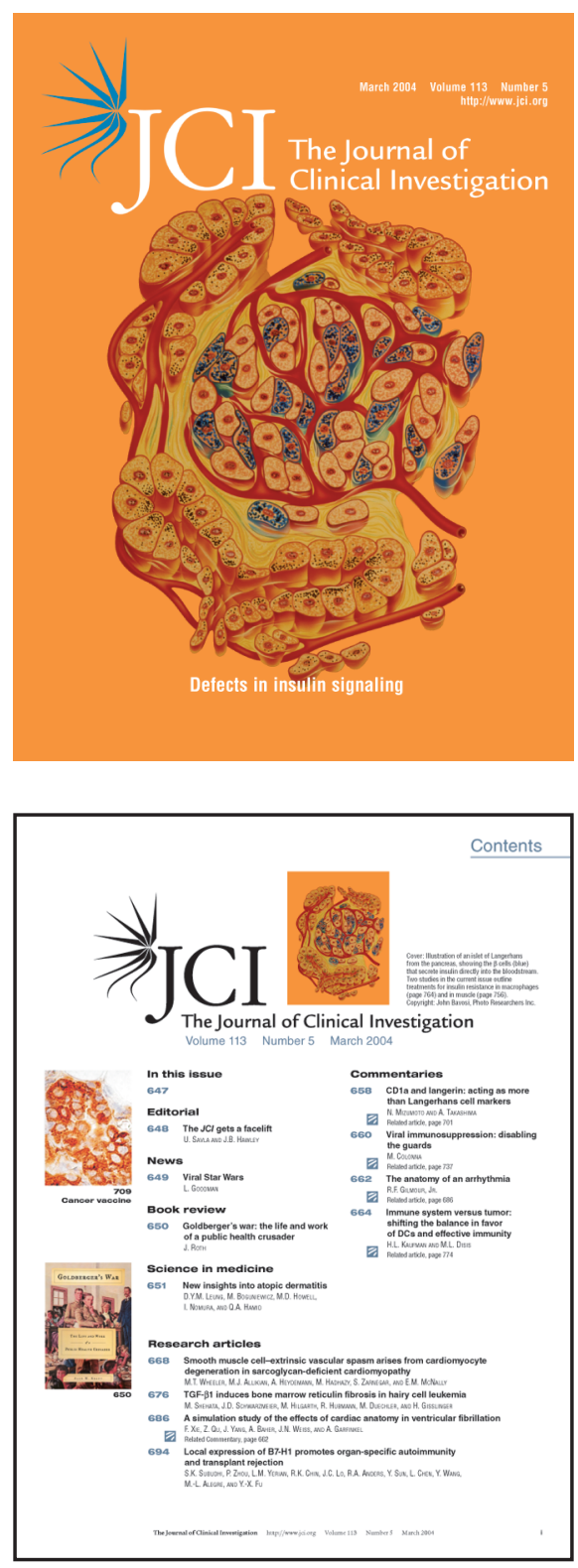

the print version, it was important to properly acknowledge that many readers are using the $J C I$ on an article-by-article basis. And as unrestricted access to $J C I$ articles is offered online, our Internet readership continues to grow. We hope that the redesign in part serves to announce to readers that they are, indeed, reading a JCI article and that the identity of a JCI page becomes easily recognizable as a sign of a high-quality publication that has been vetted by leaders in their fields and edited and produced with exacting standards.

We recognize the growing relevance of our online readership, and perhaps the primacy of the online version over the print version - how easily it can be searched, cited, linked to, and redistributed, as well as augmented by supplementary data and responses from readers. An investment in our print version, then, might seem a wasted effort. However, 5,000 print subscribers is not a small group, and they deserve a version of the journal that, while bound to the non-digital world, is as easy to read as the online version. Most importantly, the redesign provides an easy flow from article to article, and in particular it affords better browsing of the front matter, a growing part of the JCI in which we continue to invest significant time and monetary resources. We believe the readers still thumbing through our pages will be convinced they've received a nice, updated package with this redesigned issue.

With each issue, we build on our expertise and your feedback to present more cutting-edge research articles, comprehensive reviews, and in-depth analyses of novel findings, and we have headed into new territory while remaining focused on providing high-quality content relevant to your interests. Our look has changed, but our goals have not. We welcome your feedback at editors@the-jci.org.

\section{Ushma Savla Executive Editor \\ John B. Hawley Executive Director}

1. Marks, A.R. 2003. The JCI starts two new series: Science in Medicine and Science and Society. J. Clin. Invest. 111:289. doi: 10.1172/JCI200317756. 